sulfate tends to low results, while the nitrate has the opposite effect. Only by chance will these errors cancel one another. ${ }^{1}$ A few determinations made with double the usual amounts of reagents seem to show that the net error due to occlusion is sma1l.

The present paper is a preliminary one, and it is intended to publish a more detailed discussion of the whole subject later on.

\section{SUMUAAz $Y$}

The desirability of investigating the possible effect of sulfut compounds on the properties of lubricating oils is pointed out.

The disadvantages of the methods now in general use for the determination of sulfur are indicated.

A new procedure, which gives results at least as accurate as those by the bomb calorimeter, is described.

\section{DETERMINATION OF MINUTE QUANTITIES OF OIL IN SULFUR}

By L. S. Bushnell and H. Smith Clark

FREEPORT SULPHUR COMPANX, FKERPORT, TKXAS Received November 25,1919

The presence of very small amounts of oil in sulfur is objected to by manufacturers of certain sulfur products. The sulfur may contain carbonaceous residues from burned oil, and the method here described is not intended to include these.

The estimation of oil by simple extraction as ordinarily made with a volatile solvent-such as sulfuric ether or petroleum ether-will not suffice in the case of sulfur, because, while the sulfur is only slightly soluble, there is usually such a small amount of oil present (from 0.00 I per cent to 0.32 per cent, or more) that the extract contains considerably more sulfur than oil. In this method extraction is made as usual, and the solvent purified from sulfur by boiling it in a Wiley continuous extractor in which has been placed a roll of copper foil.

\section{APUARATUS}

A sheet of copper foil $4 \mathrm{in.} \times x_{5}$ in. is rolled up in such fashion that no two points of its surface come in contact. It is desirable that the copper sheet be rolled uniformly so that there will be a space of about threesixteenths inch between any one turn of the roll and the next turn. The sheet may be cut so that at one corner a tab three-eighths inch square projects. A hole is punched in this tab so that the coil may be lifted from the Wiley tube with a wire hook. The end with this tab should be rolled first, and the tab project from one end of the coil.

A 100 cc. volumetric flask; a thin glass beaker, tall form, without lip, $300 \mathrm{cc}$. capacity; and a Wiley continuous extractor, without crucible or thimble, complete the required apparatus.

\section{PROCEDURE}

Fifty grams of the pulverized sulfur (or a smaller quantity, if the oil content is known to be high) are weighed and transferred to the roo cc. flask. On this are poured about $50 \mathrm{cc}$. of redistilled petroleum ether;

1 Allen and Johnston, J. Am. Chem. Soc, 32 (1910), 588; Johnston and Adams, Ibid., $\mathbf{3 3}$ (1911), 829. the flask is thoroughly shaken every half hour for several hotus, and allowed to settle. The petroleum ether is decanted through a filter into a Wiley tube, and a second smaller quantity of the solvent is added to the flask, shaken, settled, and filtered, as betore. The washing is continued in this way until the sulfur and the fitter paper are free of oil, and the Wiley tube contains about $\mathrm{I} 75 \mathrm{cc}$. of solvent, or enough to fill the tube above the top of the copper roll or coil.

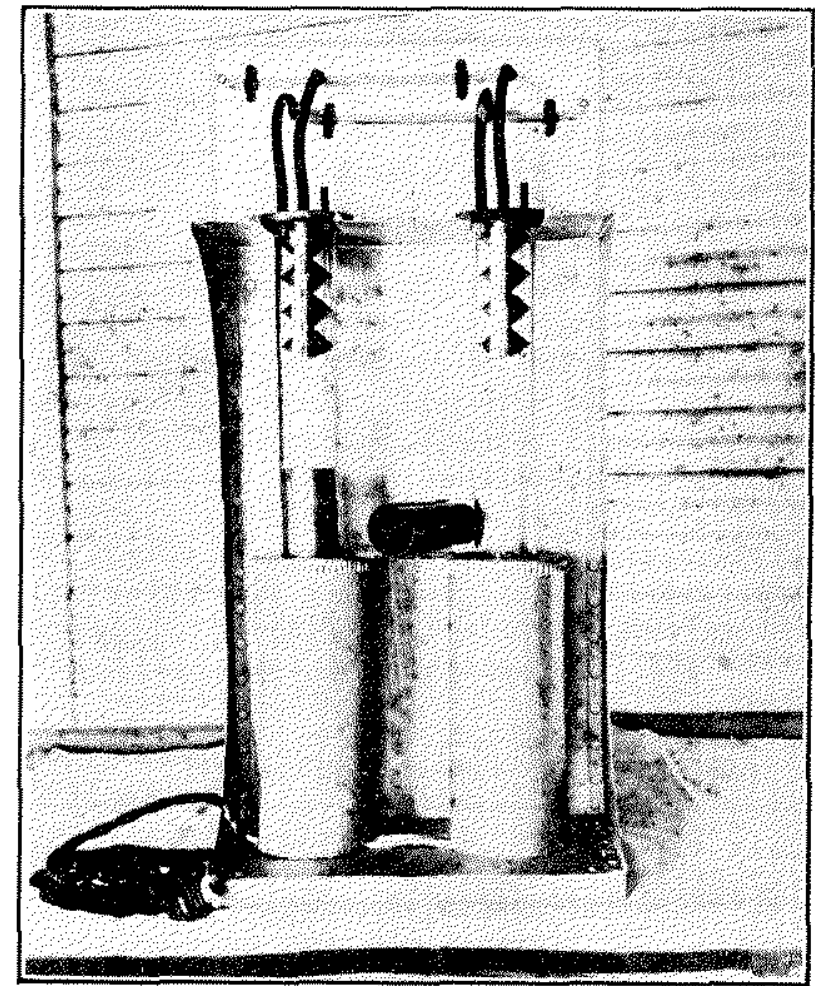

The copper coll is cleaned with dilute nitric acid, washed with water, then with alcohol, dried with ether, and placed in the Wiley tube. The petrolenm ether is then boiled until all of the sulfur has been deposited on the copper as copper sulfide.

The solvent is transferred to the tall beaker, filtering if necessary to eliminate the copper sulfide, which will doubtless partially flake off. The coil, the Wiley tube, and the filter are washed with small quantities of petroleum ether, the combined filtrate and washings gently evaporated to dryness at very low heat, and the residue weighed.

\section{NOTE ON THE SOLUBILITY OF BENZIDINE SULFATE IN WATER}

By C. S. Bisson and A. W. Christie

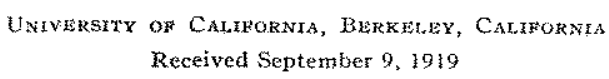

One of the methods for the determination of sulfates which has found considerable application consists in precipitation as benzidine sulfate, which may be quantitatively titrated with standard alkali or potassium permanganate. In most of the articles de. scribing such methods, the benzidine sulfate is said to be insoluble in water. A review of the literature 
failed to reveal any definite data on its solubility except a statement by Muller ${ }^{1}$ which gives it as from 0.01 to 0.03 per cent at $25^{\circ} \mathrm{C}$. We have determined its solubility at different temperatures by agitating an excess of benzidine sulfate with pure water in a constant temperature thermostat.

The benzidine sulfate was prepared by adding an excess of dilute sulfuric acid to an aqueous solution of Kahlbaum's benzidine. The precipitated sulfate was filtered and washed with distilled water till free of acid. From 3 to $5 \mathrm{~g}$. were placed in a $500 \mathrm{cc}$. Pyrex flask containing pure water and the flask immersed in a thermostat which was regulated to $0.5^{\circ} \mathrm{C}$. The contents of the flask were continually agitated by a revolving glass stirrer. After a specified number of days the solution was removed and immediately filtered, the first $20 \mathrm{cc}$. of filtrate being discarded. Solubility determinations were made at $0^{\circ}, 25^{\circ}, 50^{\circ}$, and $80^{\circ} \mathrm{C}$.

Two methods for determining the solubility of the benzidine sulfate were used. One method consisted in evaporating a measured volume of roo or $200 \mathrm{cc}$. to dryness in a platinum dish on the steam bath. The residue was dried at $100^{\circ} \mathrm{C}$, cooled in a desiccator, and weighed. The other method consisted in titrating a measured volume of the solution with $0.05 N$ potassium permanganate after the addition of 5 per cent of sulfuric acid. The latter method is described in detail elsewhere. ${ }^{2}$

1 Ber., 35 (1902), 1587

2 A. W. Christie and C. S. Bisson, Thrs Journal, 12 (1920), 171.
The solubility of benzidine sulfate in water as determined by the above methods is given in the accompanying table.

Solubility of Benzidine SULFATE IN WATER AT VARtous TeMperatures

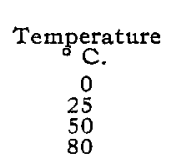

$\begin{array}{cc}\text { By Weight } & \text { Determination- } \\ \text { G. per Litration } & \text { G. per Liter } \\ 0.049 & 0.048 \\ 0.098 & 0.096 \\ 0.141 & 0.149 \\ 0.290 & 0.252\end{array}$

The two methods gave concordant results at all the temperatures except $80^{\circ} \mathrm{C}$. The solutions for the determination of solubility at $0^{\circ}$ and $25^{\circ} \mathrm{C}$. were stirred in the thermostat for four days. Those at $50^{\circ}$ and $80^{\circ} \mathrm{C}$. remained in the thermostat only $24 \mathrm{hrs}$., since it was found that after several days the solutions became badly discolored, indicating that the benzidine sulfate had undergone decomposition. The solution obtained at $80^{\circ} \mathrm{C}$. was slightly discolored even after $24 \mathrm{hrs}$, as was also the residue obtained on evaporation. This is probably due to the partial oxidation of the benzidine at the higher temperature, as evidenced by the low figure for solubility obtained by titration. The residue obtained from the $50^{\circ}$ solution showed only a very slight discoloration and the results may be considered to give the approximate solubility at this temperature.

From a consideration of these restilts it is evident that in washing the benzidine sulfate in a quantitative determination of sulfate, the minimum amount of cold water should be used.

\section{LABORATORY AND PLANT}

A CONVENIENT METHOD FOR THE DETERMINATION OF WATER IN PETROLEUM AND OTHER ORGANIC EMULSIONS ${ }^{1}$

By E. W. Dean and D. D. Stark

Chemical Section, Petrolaum Division, U. S. Bureau of Mines, PITtSBurgh, PA.

Received January 15, 1920

INTRODUCTION

One of the problems frequently confronting the petroleum chemist is the determination of emulsified water. Numerous methods have been devised, several of which have been described in a previous publication $^{2}$ issued by the Bureau of Mines. Allen and Jacobs discuss in that paper the advantages and limitations of various types of procedure and recommend as most desirable the scheme of distilling in a special electrically heated still. This type of still involves heating the entire outer surface of a $250 \mathrm{cc}$. distilling flask and its use permits the "breaking" of troublesome froth that is usually formed when a viscous petroleum emulsion is heated. Certain difficulties in the construction and operation of this still have led to discontinuing its use in favor of the more common method of diluting the emulsion before distillation with a solvent immiscible with water. The present Mines,

${ }_{1}$ Published by the permission of the Director of the U. S. Bureau of

2 See Bibliography, p. 490. paper reports the work of the Bureau in modifying this latter method to obviate certain of its admitted disadvantages.

DISTILLATION IN THE PRESENCE OF AN IMMISCIBLE SOLVENT

There are various conditions under which it is desirable to determine water in petroleum emulsions and no one method is best in all cases. The method of gravity separation ${ }^{1}$ is a convenient one and is satisfactorily reliable for emulsions that are not too viscous or that contain water in not too fine a state of subdivision. For the estimation of extremely small percentages of water, in such products as transformer oils, special methods are necessary which are too delicate for ordinary needs. The distillation method is without doubt most generally applicable, highly reliable, and sufficiently accurate for all usual requirements. The use of a solvent not miscible with water offers several advantages, the most important of which is prevention of frothing. Its principle disadvantages concern details of operation, and the modified procedure described in the present paper has been found to obviate most of these difficulties.

This method of determining water has been used in a

1 A common procedure is to place a measured volume of oil in a suitable graduated tube, dilute with naphtha, and spin in a centrifuge. The water is driven to the bottom of the graduated tube and its volume can be read directly. 